\title{
Rapid Growth of Very Large KDP and KD*P Crystals in Support of the National Ignition Facility
}

R. Hawley-Fedder, H. Robey, T. Biesiada, M. DeHaven, R. Floyd, and A. Burnham

This article was submitted to Society of Photo-Optical Instrumentation Engineers $45^{\text {th }}$ Annual Meeting, San Diego, CA, July 30 - August 04, 2000

June 22, 2000 


\section{DISCLAIMER}

This document was prepared as an account of work sponsored by an agency of the United States Government. Neither the United States Government nor the University of California nor any of their employees, makes any warranty, express or implied, or assumes any legal liability or responsibility for the accuracy, completeness, or usefulness of any information, apparatus, product, or process disclosed, or represents that its use would not infringe privately owned rights. Reference herein to any specific commercial product, process, or service by trade name, trademark, manufacturer, or otherwise, does not necessarily constitute or imply its endorsement, recommendation, or favoring by the United States Government or the University of California. The views and opinions of authors expressed herein do not necessarily state or reflect those of the United States Government or the University of California, and shall not be used for advertising or product endorsement purposes.

This is a preprint of a paper intended for publication in a journal or proceedings. Since changes may be made before publication, this preprint is made available with the understanding that it will not be cited or reproduced without the permission of the author.

This report has been reproduced directly from the best available copy.

Available electronically at http://www.doc.gov/bridge

Available for a processing fee to U.S. Department of Energy

And its contractors in paper from

U.S. Department of Energy

Office of Scientific and Technical Information

P.O. Box 62

Oak Ridge, TN 37831-0062

Telephone: (865) 576-8401

Facsimile: (865) 576-5728

E-mail: reports@adonis.osti.gov

Available for the sale to the public from

U.S. Department of Commerce

National Technical Information Service

5285 Port Royal Road

Springfield, VA 22161

Telephone: (800) 553-6847

Facsimile: (703) 605-6900

E-mail: orders@ntis.fedworld.gov

Online ordering: http:/ / www.ntis.gov/ordering.htm

\section{OR}

Lawrence Livermore National Laboratory

Technical Information Department's Digital Library

http: / / www.llnl.gov/tid/Library.html 


\title{
Rapid Growth of Very Large KDP and KD*P Crystals in Support of the National Ignition Facility
}

\author{
Ruth Hawley-Fedder*, Harry Robey, Tom Biesiada, \\ Martin DeHaven, Randy Floyd, Alan Burnham \\ Lawrence Livermore National Laboratory, P.O. Box 808, Livermore CA 94551
}

\begin{abstract}
The National Ignition Facility will require hundreds of very large single crystals (boules) of KDP and $\mathrm{KD} * \mathrm{P}$ for the amplifier and frequency conversion optics. Rapid growth now routinely produces $250-300$ $\mathrm{kg}$ boules of KDP. Technical hurdles overcome during the past year include inclusion formation and spurious nucleation. Areas of continued interest are control of asymmetry and aspect ratio.

Variations in KDP concentration on the $\mu \mathrm{m}$ scale at the growing crystal steps can cause inclusions of growth solution. Microscopic investigations, hydrodynamic modeling, and theoretical modeling have been combined to provide a good mechanistic understanding of the formation of inclusions. Modifications to rotation regimes to improve hydrodynamics can eliminate or minimize the effects of these instability mechanisms, and can increase the inclusion-free growth rate by $20-40 \%$ over previously observed growth rates.

Aspect ratio and boule asymmetry remains of great interest. Small changes in asymmetry can result in significant increases in maximum yields for boules of the same mass. Reasons for the observed changes in aspect ratio during growth will be presented, along with methods to control or influence aspect ratio and boule asymmetry.
\end{abstract}

Keywords: KDP, KD*P, rapid growth, large crystals, NIF, inclusions, aspect ratio, large crystals

\section{INTRODUCTION}

The National Ignition Facility currently under construction at Lawrence Livermore National Laboratory (LLNL), has been designed to permit the study of fusion of atomic nuclei ${ }^{1}$. NIF will utilize 192 laser beams to produce 1.8 megajoules of energy and 500 terawatts of power. Each laser beamline requires three separate large aperture $(42 \mathrm{~cm} \times 42 \mathrm{~cm})$ optical components that are cut from single crystal potassium dihydrogen phosphate $\left(\mathrm{KH}_{2} \mathrm{PO}_{4}\right.$, or $\left.\mathrm{KDP}\right)$ boules. These optical components are the Pockels cell switch crystals (SC) and Final Optics Assembly second and third harmonic generation crystals (SHG and THG). THG crystals are fabricated from KDP in which most of the hydrogen atoms have been replaced by deuterium. Deuterated KDP is often referred to as DKDP or KD*P. The location of the various crystal types, as well as their orientation within the KDP crystal boule, is shown in Figure 1. 


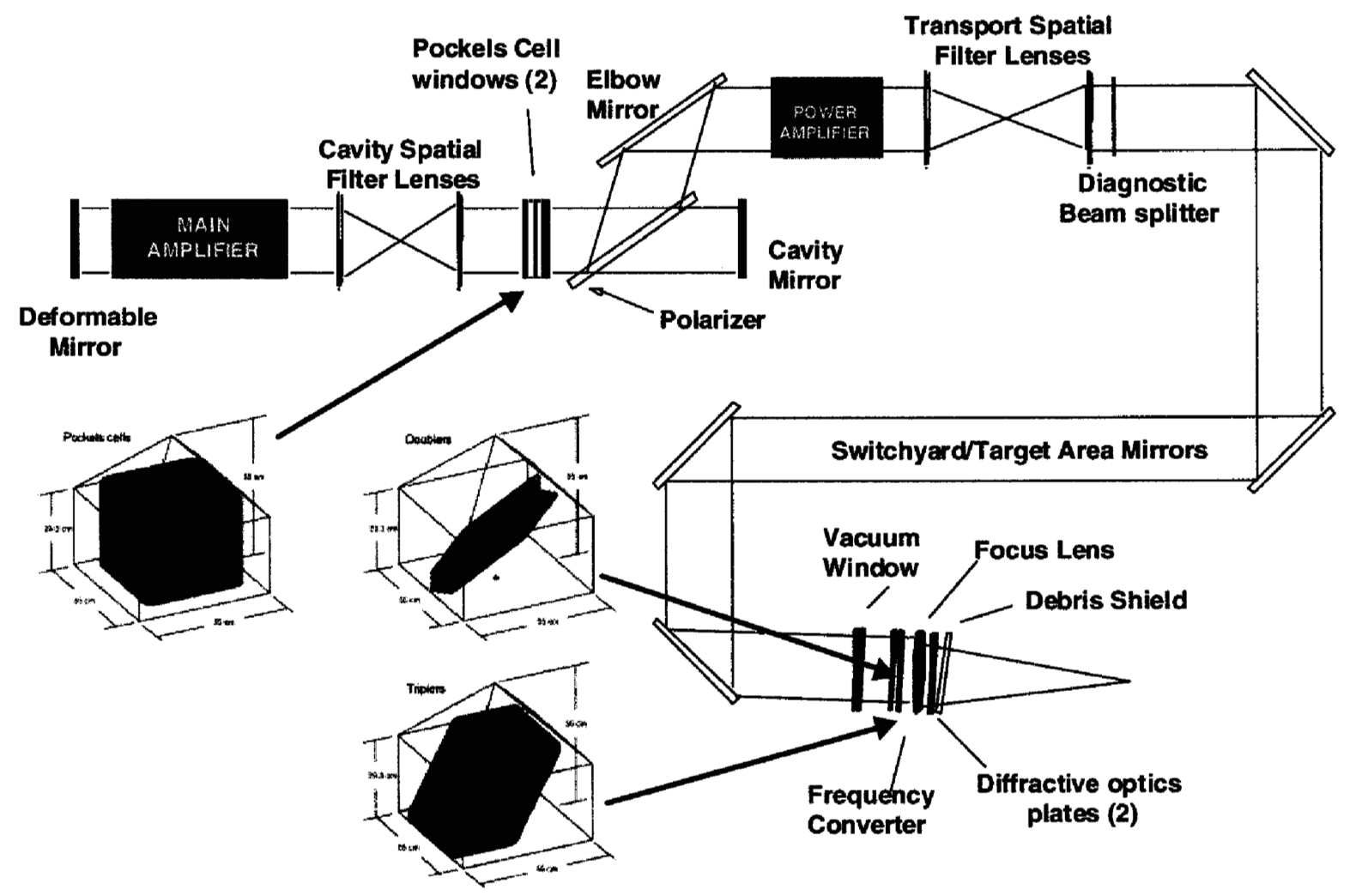

Figure 1. Schematic of the NIF laser showing the location of the KDP and KD*P components. Also shown are the orientation of the conversion crystals within the boules.

In order to produce the over 600 very large optics required for the NIF, boules of very large size (nominally $55 \mathrm{~cm}$ by $55 \mathrm{~cm}$ by $55 \mathrm{~cm}$ ) must be grown. ${ }^{2}$ In addition to the requirement of very large size, the boules must be of high quality. Essentially all the KDP and up to half the KD*P for the NIF will be supplied by rapid growth technology. Substantial progress has been made since late 1998 in overcoming some of the technical hurdles that prevented us (LLNL and our commercial partners, Cleveland Crystals, Inc., and Inrad Corp.) from consistently growing NIF quality KDP material. This article reviews the advances that have resulted in more than two of three rapid growth runs producing NIF-size crystals with no significant inclusions. As of July, 2000, more than half of the switch crystals and about one-third of the doubler crystals have been grown for the NIF.

\section{Spurious Crystals}

LLNL rapid growth technology is based on growth over point seeds by temperature reduction in Holdentype crystallizers using supersaturations of $3-10 \%$, depending on temperature and desired growth rate. ${ }^{2}$ Stability tests have shown that supersaturations of 30-100\% can be obtained in 5-L crystallizers from 65 to $10^{\circ} \mathrm{C}$, independent of dissolved impurities. ${ }^{3}$ The challenge for scaleup is to eliminate all sources of heterogeneous nucleation, such as cracks and joints in the crystallizer and continuous filtration plumbing. Continuous filtration is necessary to grow crystals with high laser damage resistance. ${ }^{4}$

By early 1998, rapid growth of NIF-size boules had been demonstrated in principle, but the process was very far from being a viable production method. The primary cause of early run termination was the formation of spurious "Crystals on the Bottom", or COBs, that normally first appear on the bottom of the growth tank. Within days, some usually fall on one or more faces of the boule, thereby spoiling any subsequent growth. A historical record of run termination in 1000-L production tanks at LLNL is given in Figure 2 . 


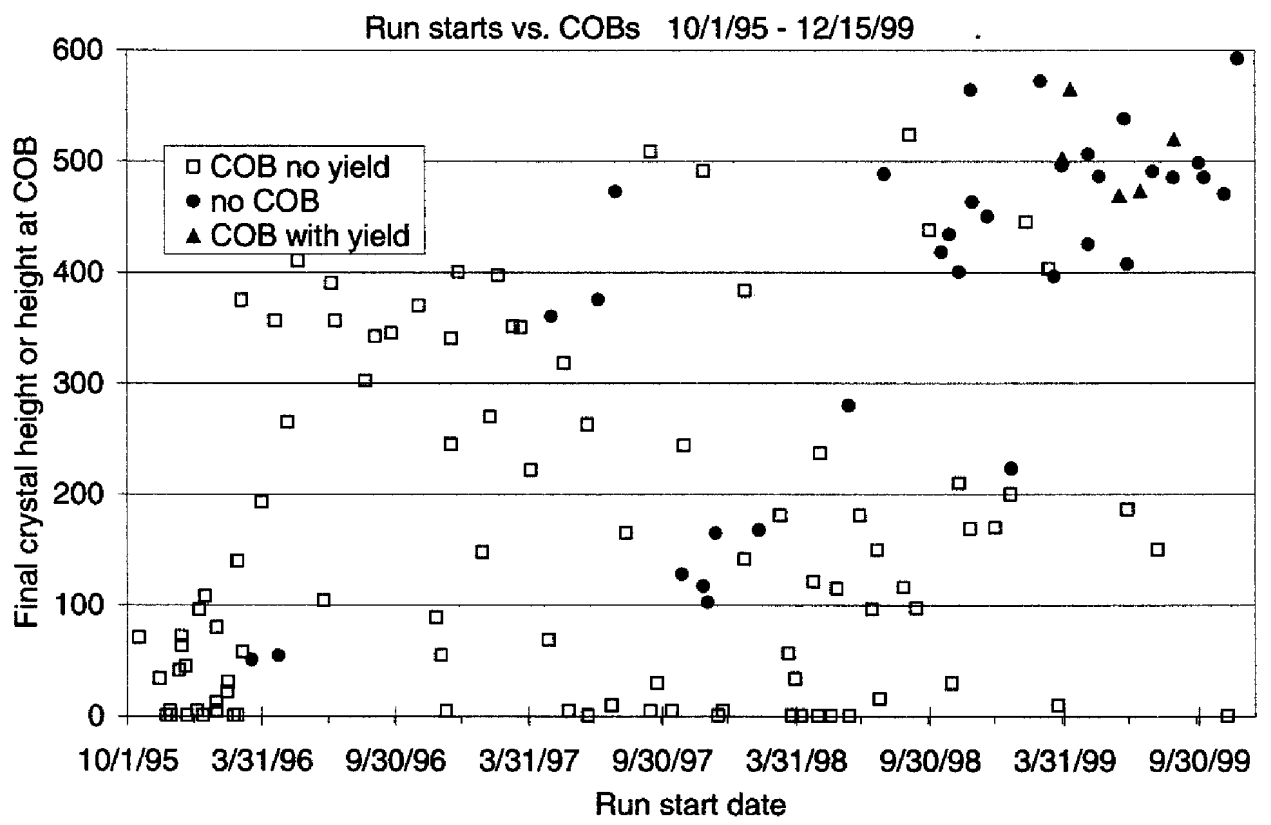

Figure 2. Historical record of $1000-\mathrm{L}$ crystallizer termination showing that most runs prior to October 1998 ended prior to NIF size due to "Crystals on the Bottom." Boules must have a minimum height of about $400 \mathrm{~mm}$ to yield switch crystals and about $500 \mathrm{~mm}$ for doubler and tripler crystals, depending on asymmetry. Quality as well as size determines yield.

The occurrence of spurious crystals was drastically reduced over the past two years by a combination of equipment modification and careful attention to detailed written procedures for assembly and preliminary filtration and overheating. For example, the occurrence of spurious crystals in the first ten days was reduced from $41 \%$ to $7 \%$ between the 12 months preceding and following October 1998 . Design and fabrication of streamlined aluminum growth platforms coated with a non-leaching Halarß coating eliminated the glued joints and crazing associated with earlier acrylic platforms as well as possible shedding of a nucleus from the growing crystal due to platform deformation. O-rings used to seal the seedprotector shaft are more carefully matched to the internal platform shaft diameter. Continuous filtration systems were modified for increased reliability. Platform rotation is slowed when the crystal becomes very large to minimize the surface wave and associated splashing. The detailed procedures were also important for successful transfer of the process to our commercial partners.

\section{Inclusion Formation}

A major issue in rapid growth of KDP and $\mathrm{KD} * \mathrm{P}$ is the formation of solution inclusions. Solution inclusions occur when crystal growth results in the trapping of small (micron-sized) bubbles of solution. The mechanics of growth that result in this trapping of solution are primarily dependent upon two factors solution hydrodynamics and solution purity. Ideal crystal growth on the pyramid face occurs by atomic steps spiraling from a dislocation. ${ }^{5}$ Both poor mass transfer and pinning of the elementary steps by impurities can cause nonideal growth due to bunching of elementary steps into macrosteps, and these macrosteps can lead to inclusions in some circumstances.

Microscopic investigations, hydrodynamic modeling, and theoretical modeling have been combined to provide a good mechanistic understanding of the formation of inclusions. A micrograph of one type of unstable growth by macrosteps is shown in Figure 3, in which "fingering" is apparent on the advancing growth macrostep. ${ }^{6}$ Fingering is caused by lateral instability in which the supersaturation at the tips of the fingers is higher than the supersaturation experienced by the growing step in the cavities between the fingers. Although thermodynamics promote the filling of cavities between the fingers during slow growth, kinetics can cause the fingers to grow catastrophically, thereby surrounding and occluding growth solution. 
Solution moving in the opposite direction of the step advance is depleted in concentration as it moves past the tips of the fingers and towards the cavities, thereby causing a faster growth rate at the tip of the finger than at the base. Rapidly alternating the direction of flow helps prevent this catastrophic growth. Hydrodynamic modeling studies support the thesis that rapid rotation is necessary to provide more uniform feeding of the growing crystal surfaces. ${ }^{7}$ As the rotation is increased from $30 \mathrm{rpm}$ to $50 \mathrm{rpm}$, the supersaturation experienced at the center of the growth face more closely approaches that of the bulk solution. In addition, the difference in supersaturation between the center of the crystal face and the edges of the crystal face decreases.

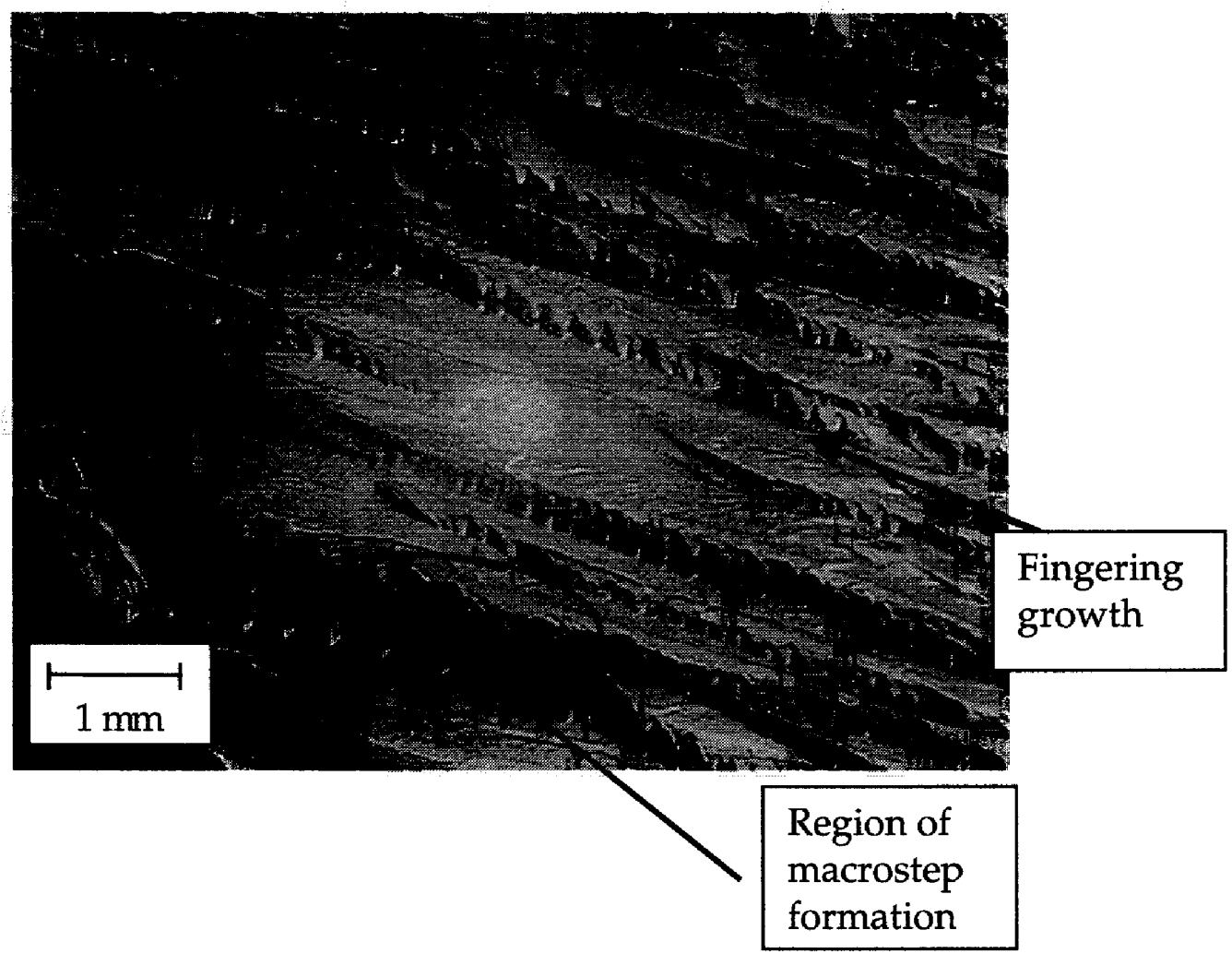

Figure 3. Fingering growth of macrosteps on the KDP surface.

A second type of instability involves the bunching and bending of elementary growth steps into macrosteps due to inadequate stirring. An example of this type of growth is also shown in Figure $3 .^{6}$ Macrosteps are the result of longitudinal instability on the crystal surface caused by depletion of KDP from solution near the growing surface. This depletion results in localized changes in individual step growth rates. Faster growing steps will overtake slow steps, resulting in the formation of macrosteps consisting of bunches of elementary steps. The formation of macrosteps can be controlled by changing the direction and speed of rotation of the growing crystal, as well as by changing the supersaturation. Although not a problem by themselves, when macrosteps from two sides of a growth hillock bend around and approach each other from the opposite direction, a deep valley can be formed. Inclusions also tend to form in the vicinity of this valley. Valley formation can be minimized by rapid rotation, thereby keeping the solution concentration in the center of the crystal face closer in magnitude to that along the edges. Figure 4 is a surface topographic plot of one pyramidal face of a small KDP boule, showing step bending at the crystal edges leading to the formation of a valley (dark purple region), which resulted in the formation of a solution inclusion. ${ }^{8}$

Bunching of macrosteps and step bending is usually observed when growth rates are too high for existing conditions of hydrodynamic flow and crystal feeding. Even with rapid rotation changes to minimize inclusion formation, variation in KDP concentration on the micrometer scale at the growing crystal steps can cause inclusions of growth solution. These inclusions can easily be large enough to cause more 
obscuration by scattering than can be tolerated in the laser. Through a combination of fundamental studies and growth experiments at various scales over the two years, we have shown that better mass transfer by increased acceleration and rotation rates can increase the inclusion-free growth rate by $20-40 \%$ over what was previously possible. Figure 5 summarizes much historical data on the occurrence of pyramidal inclusions in 1000-L growth tanks through 1998, indicating that pyramidal inclusions are much more prevalent at high growth rates. The same trend occurs for prismatic inclusions. This presents the crystal grower with a dilemma - how to avoid the detrimental effects of impurity buildup and associated degradation of prismatic KDP that occurs at slow growth rates while avoiding the potential formation of massive pyramidal inclusions at high growth rates. The best-quality NIF-size KDP boule grown as of late 1998 followed the solid triangle growth trajectory also shown in Figure 5, substantially above that previously considered safe. The streamlined, Halar ${ }^{\circledR}$-coated, aluminum growth platforms were important for achieving these higher rotation rates. The combination of improvements in the growth hardware and increased understanding of the mechanisms of inclusion formation means that these type of inclusions are now rarely seen in rapid growth $\mathrm{KDP}$ and $\mathrm{KD} * \mathrm{P}$ boules.

\{101\} face *3 contours
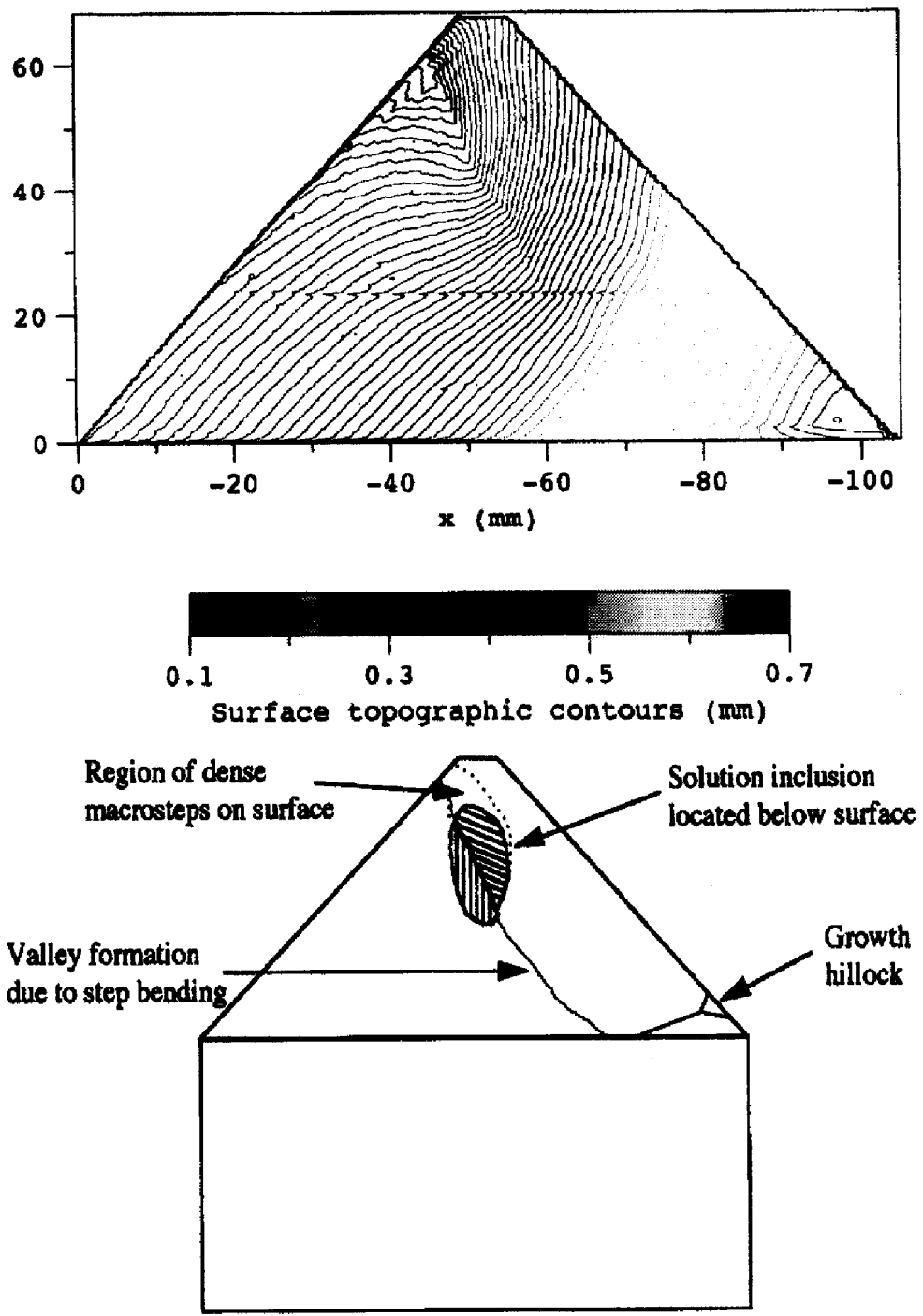

2(b) Sketch of $\{101\}$ face $\$ 3$ surface features

Figure 4. Contour plot of the $\{101\}$ face of a KDP boule, showing valley formation due to step bending (top). Location of the solution inclusion is indicated by crosshatching (bottom). 


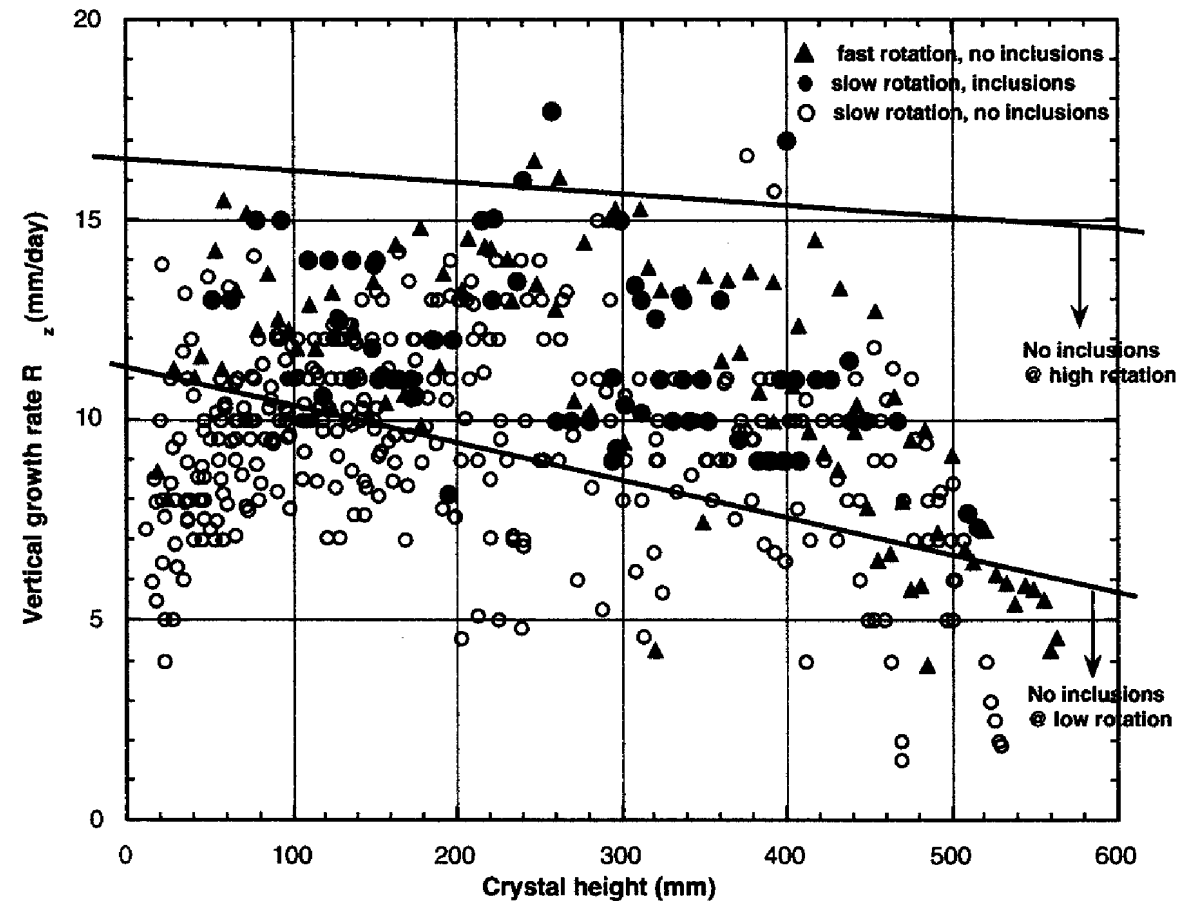

Figure 5. Summary of 1000-L growth tank data showing the relationship between pyramidal inclusions and growth rates for slow and fast rotational regimes. For runs prior to late 1998, the rotational rate was typically 25 rpm, while the high rotation rate during the recent run represented by the filled squares was at $50 \mathrm{rpm}$.

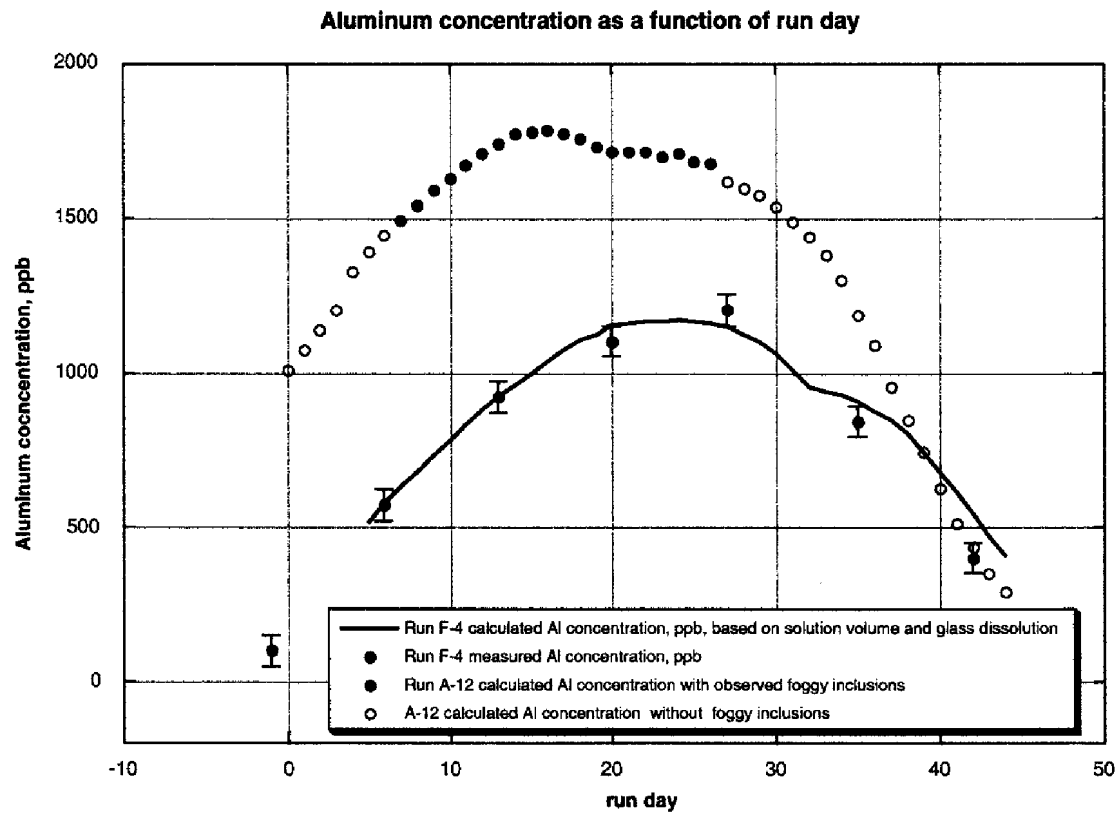

Figure 6. Comparison of occurrence of foggy inclusions with measured and calculated aluminum concentration in the growth solution as a function of time. The aluminum concentration initially rises as the rate of glass tank solution dominates when the crystal is small; it later falls because the rate of uptake in the prism face increases with crystal size and exceeds the glass dissolution rate, which is dropping with temperature. 
Though usually inert, there is a finite rate of tank dissolution in the hot KDP solutions used for rapid growth. ${ }^{9}$ Using measured Pyrex dissolution rates and the uptake coefficients for various impurities in the prism sector, ${ }^{3}$ we successfully modeled the buildup and eventual consumption of $\mathrm{Al}$ and $\mathrm{Fe}$ in the growth solution. In solutions with high concentrations of aluminum (greater than $1400-1600 \mathrm{ppb}$ ), foggy inclusions are usually observed at the prism sector boundaries (corners). Figure 6 shows the typical aluminum concentration profile (both calculated and measured) observed for a growth run, as well as the calculated impurity profile for a growth run in which foggy inclusions were observed. These inclusions are believed to be sub-micron-sized bubbles of trapped solution and occur only near the prism sector boundaries. The exact mechanism of solution trapping leading to the inclusions is not known, but the presence of these foggy inclusions is a cause for concern when specifications for maximum scattering losses are considered. Foggy inclusion can be avoided by keeping solution Al levels below a maximum of about $1600 \mathrm{ppb}$, and they can be minimized by growth at supersaturation near $3 \%$ and high rotation. Polycarbonate tanks are currently being tested to eliminate this problem. The polycarbonate tanks will also enable the use of a slightly larger growth platform, which will help alleviate the aspect ratio limitations discussed in the next section.

\section{Boule Asymmetry and Aspect Ratio}

With the resolution of previous problems associated with spurious crystallization and inclusion formation, our efforts now have focused on defining the parameters that will allow us to reproducibly control the crystal asymmetry and aspect ratio. Boule asymmetry is predominately determined by the relative growth rates of the various prism faces. Different asymmetries are most favorable for the different crystal types: symmetric for switch crystals, barn-shaped (two opposite prisms having a faster growth rate) for triplers, and skewed (two adjacent prism faces having a faster growth rate) for doublers. Aspect ratio, defined as the ratio of boule height to average base width, is also important for determining the final crystal yield from a boule. For symmetrical boules with dimensions of $55 \times 55 \times 55 \mathrm{~cm}$, the maximum possible plate yield is 5 doubler crystals (KDP) and 17 tripler crystals $\left(\mathrm{KD}^{*} \mathrm{P}\right)$. If the boule dimensions change to $50 \times 62 \times 62$ $\mathrm{cm}$, corresponding to an aspect ratio of 0.8 , the doubler yield is still 5 plates, but the tripler yield is zero. Because of the plate geometry within the boule, $\mathrm{KD} * \mathrm{P}$ must be at least $54.8 \mathrm{~cm}$ tall before any yield is realized. Achieving these sizes is a challenge in the current size equipment, which was designed for $39-\mathrm{cm}$ plates.

Regardless of boule asymmetry, the aspect ratio of a growing boule changes throughout the growth run. Immediately after regeneration, most boules display an aspect ratio close to 1 . The aspect ratio then decreases steadily for the first 10-14 days of the growth run, or until the crystal base reaches between 10-12 $\mathrm{cm}$. At this point, the aspect ratio begins to increase. This change corresponds to the point during growth when the prism faces enter grooves on the growth platform. Figure 7 is a plot showing the change in aspect ratio for a series of NIF-sized boules grown at LLNL. When the growth rates of the various crystal faces are compared, it is seen that the observed increase in aspect ratio is due primarily to a reduction in prismatic growth rates. When the change is aspect ratio as a function of run day is modeled for the case of constant and equal growth rates for all faces (prism and pyramid), the aspect ratio reaches a natural limit of approximately 0.71 . The question then arises as to why an increasing aspect ratio is observed at about two weeks into the growth run.

No single factor can be identified as the primary cause of the decrease in prism growth rate. In fact, there are several competing factors that contribute to the observed change in the growth rate of the prism faces.

At about the same time as the aspect ratio begins to increase, there is an observed change in the location of the growth hillocks on the prisms. As the prism faces enter the grooves, the dislocation structure of the faces changes and the growth hillocks move toward the center of the prisms. This movement of the hillocks must be due to the presence of a strong dislocation source at the grooves. A dislocation source strong enough to move growth hillocks as is observed would be expected to result in an increased growth rate for the prism faces. Solution impurities are also increasing until about day 25-30 of the growth run. 


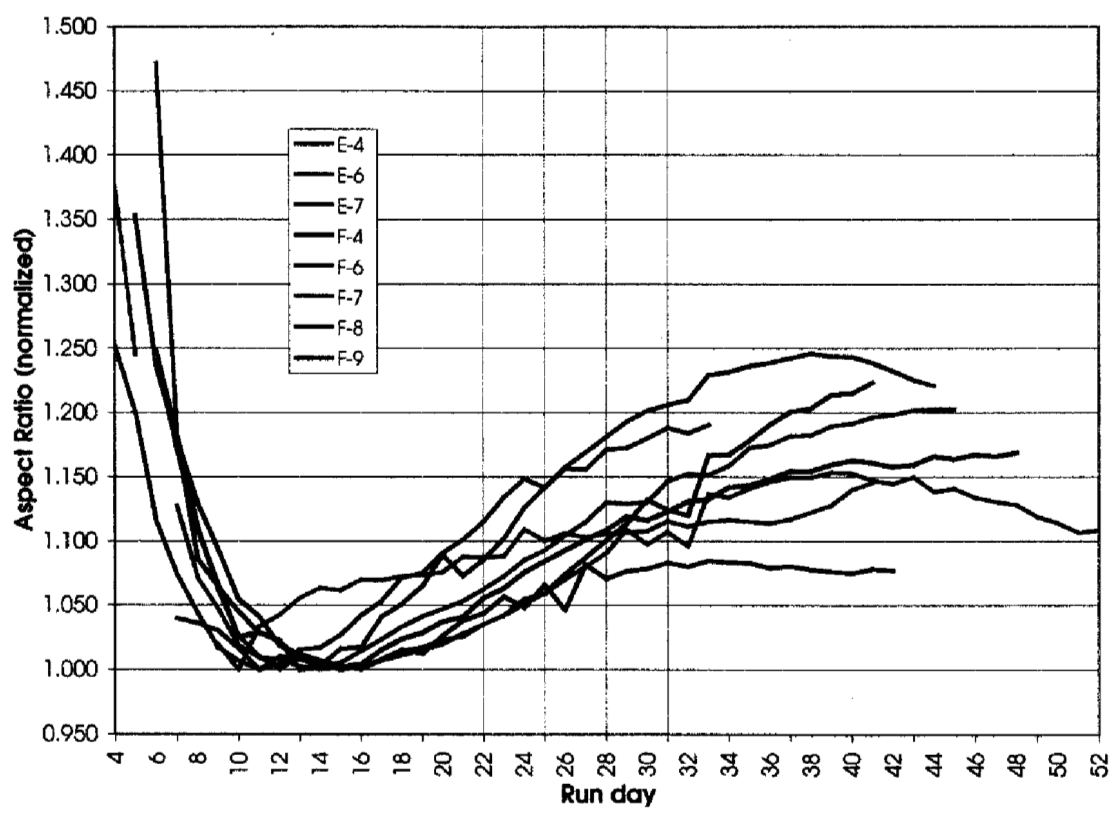

Figure 7. Aspect ratio change as a function of growth run day. We currently think that impurity poisoning from dissolution of the Pyrex@ crystallizer is the primary cause of this increase.

Prismatic growth is especially sensitive to impurity concentration, and higher impurity levels which cause pinning of atomic steps on the surface are expected to lead to a decrease in growth rate on the prism faces. $^{10,11}$ We currently think that impurity levels are the dominant factor affecting the observed change in aspect ratio, and we are measuring the effects of supersaturation, impurity levels and temperature on prismatic growth over the conditions that occur in our production process.

Besides aspect ratio, boule asymmetry can have a large effect on plate yield. Original planning estimates of plate yields were based on symmetric boules, in which all prismatic growth rates are equal. However, the prismatic faces normally grow at slightly different rates, resulting in crystals that are either barn shaped (two opposite prism faces grow faster) or skewed (two adjacent prism faces grow faster). The latter case is especially favorable to doubler crystals yield. Growth of 15 boules large enough to yield at least one $42-\mathrm{cm}$ doubler plate provides a statistical basis for estimating average process yield. For a minimum practical yield of 4 plates per boule, the 13 qualifying boules contain 85 doubler plates. For comparison, if all boules were symmetric with the same mass and aspect ratio, only 9 boules would yield 4 or more plates, for a total of 66 plates. On average, crystal asymmetry is favorable to total doubler yield. Unfortunately, we have not yet been able to tailor asymmetry for maximum possible yield. Boules with less than 4 plates will probably be used for switch crystals.

Although the current baseline method for producing $\mathrm{KD} * \mathrm{P}$ triplers is conventional growth at Cleveland Crystals, Inc., the potential for reduced replacement costs has motivated continued development work for rapid growth KD*P. When grown rapidly from a pure solution necessary to meet quality objectives, KD*P tends to grow with an aspect ratio lower than KDP. Given the limitations in the crystal base size imposed by the existing circular growth platform diameter of $90 \mathrm{~cm}$, the height a symmetric-based crystal with an aspect ratio of 0.8 would reach is $51 \mathrm{~cm}$ high-too short for triplers. Improving aspect ratio by allowing more solution impurities to retard prism growth is undesirable, especially for $\mathrm{KD}^{*} \mathrm{P}$, which is challenged to meet a more difficult 351-nm laser damage threshold. As a result, we are exploring a variety of ways to improve both doubler and tripler yields by making more optimal shapes. A method for triplers is to grow the $\mathrm{KD}^{*} \mathrm{P}$ boule horizontally, which increases aspect ratio (now rotated) by eliminating one growth prism and adding a second pyramid. Improvements in $351-\mathrm{nm}$ laser-induced bulk damage resistance are also needed for operation at full NIF fluences, but that issue will not be discussed in this paper.

Based upon data on growth dimensions collected during growth of four NIF-sized horizontal KD*P boules at LLNL, there appear to be natural asymptotic limits to the aspect ratios for horizontally grown KD*P. 
We monitored two aspect ratios associated with horizontal $\mathrm{KD} * \mathrm{P}$ growth: the ratio of the height (prism $\mathrm{z}$ ) to width (prism y) and the ratio of the width (prism y) to length (pyramid $\mathrm{x}$ ). The length/width ratio is important as it determines the maximum size boule that will fit on the platform. The height/width ratio is important for determining when a crystal is large enough to yield tripler crystals. For horizontal growth $\mathrm{KD} * \mathrm{P}$, the minimum height for yield is $22.8 \mathrm{~cm}$, the minimum width is $43 \mathrm{~cm}$, and the minimum length is $68 \mathrm{~cm}$. Maximum dimensions are governed by the platform diameter $(90-\mathrm{cm})$ and the space available between the platform bars for removal of the boule $(65-\mathrm{cm})$. A plot of these aspect ratios is shown as Figure 8 . The height/width ratio appears to reach a constant value between 0.34 and 0.40 , where the minimum acceptable ratio is 0.357 . The implication for horizontal growth is that boules will grow to fairly large base dimensions (length and width) before the boule height reaches the minimum necessary for yield. Either increasing the vertical prism growth rate closer to the horizontal prism growth rates or increasing the platform size by only a few centimeters would make the horizontal growth process much more likely to attain minimum yield dimensions.

\section{SUMMARY}

Rapid growth of large KDP boules has become a robust production process with yields exceeding those projected during early NIF project planning purposes. The technology has been successfully transferred to commercial vendors for NIF production. ${ }^{12}$ Technical problems overcome to attain this robust process were minimizing the occurrence of "crystals on the bottom," eliminating prismatic and pyramidal inclusions related to poor feeding and macrostep bending, and reducing foggy inclusions near prismatic edges related to high aluminum content in the growth solution. As a result, more than half of the switch crystals and about one-third of the doubler crystals needed for the NIF have been grown. In addition, more than $10 \%$ of the triplers needed for the NIF have been grown by rapid growth technology, although some improvement in laser-induced bulk damage resistance is required for use at full NIF fluences.

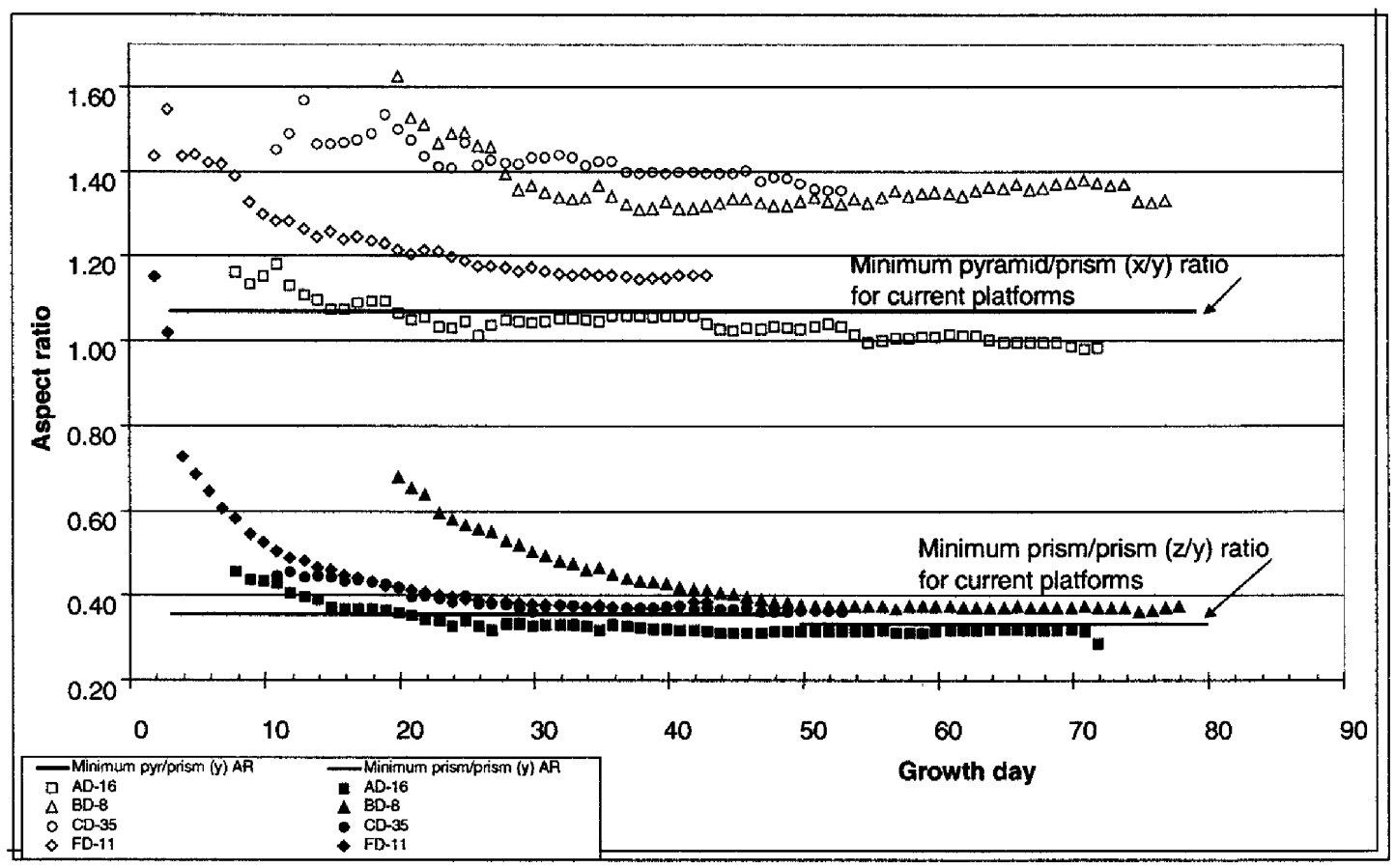

Figure 8. Observed aspect ratios for horizontal KD*P boules grown to date. Open symbols are length/width ratios; closed symbols are height/width ratios. The line at 1.06 represents the minimum length/width ratios and the line at 0.36 represents the minimum aspect ratio for height/width ratio. Run FD-11 was grown from a starting temperature of $43^{\circ} \mathrm{C}$, while all other runs were begun near $70^{\circ} \mathrm{C}$. Average growth rates were: $\mathrm{AD}-16$ vertical $3.56 \mathrm{~mm} / \mathrm{day}$, prisms 4.79 $\mathrm{mm} /$ day, pyramids $4.7 \mathrm{~mm} /$ day; BD-8 vertical $3.2 \mathrm{~mm} /$ day, prisms $4.72 \mathrm{~mm} /$ day, pyramids $6.47 \mathrm{~mm} /$ day; $\mathrm{CD}-35$ 
vertical $4.83 \mathrm{~mm} /$ day, prisms $6.47 \mathrm{~mm} /$ day; pyramids $9.13 \mathrm{~mm} /$ day; FD-11 vertical $5.67 \mathrm{~mm} /$ day, prisms $7.5 \mathrm{~mm} /$ day, pyramids $8.79 \mathrm{~mm} /$ day. 


\section{ACKNOWLEDGEMENTS}

This work was performed under the auspices of the U.S. Department of Energy by University of California Lawrence Livermore National Laboratory under contract No. W-7405-Eng-48. The authors wish to acknowledge Natalia Zaitseva and Leslie Carman for their developmental work on horizontal growth of $\mathrm{KD} * \mathrm{P}$.

\section{REFERENCES}

1. J.D. Lindl, "Development of the indirect-drive approach to inertial confinement fusion and the target physics basis for ignition and gain", Plasmas 2, pp. 3933-4024, 1995.

2. N.P. Zaitseva, J.J. De Yoreo, M.R. Dehaven, R.L. Vital, K.E. Montgomery, M. Richardson, J.L. Atherton, "Rapid growth of large scale $(40-55 \mathrm{~cm}) \mathrm{KD}$ ) crystals", J. Crystal Growth 180, pp. 255-262, 1997.

3. N. Zaitseva, L. Carman, I. Smolsky, R. Torres, M. Yan, "The Effect of impurities and supersaturation on the rapid growth of KDP crystals”, J. Crystal Growth 204, pp. 512-524, 1999.

4. N. Zaitseva, J. Atherton, R. Rozsa, L. Carman, I. Smolsky, M. Runkel, R. Ryon, L. James, "Design and benefits of continuous filtration in rapid growth of large KDP and DKDP crystals," J. Crystal Growth 197, pp. 911-920, 1999.

5. J.J. De Yoreo, T.A. Land, L.N. Rashkovich, T.A. Onischenko, J.D. Lee, O.V. Monovskii, N.P. Zaitseva, "The effect of dislocation cores on growth hillock vicinality and normal growth rates of KDP \{101\} surfaces," J. Crystal Growth 182, pp. 442-460, 1997.

6. Harry F. Robey and S. Potapenko, "Ex-situ microscopic observation of the lateral instability of macrosteps on the surfaces of rapidly grown $\mathrm{KH}_{2} \mathrm{PO}_{4}$ crystals", J. Crystal Growth 213, pp. 355-367, 2000.

7. Harry F. Robey, "A numerical study of flow augmentation options for improvement of the KDP rapid growth process," Lawrence Livermore National Laboratory, Livermore, CA UCRL-ID-133215, 1999.

8. H.F. Robey, S. Yu. Potapenko, K.D. Summerhays, "'Bending' of steps on rapidly grown $\mathrm{KH}_{2} \mathrm{PO}_{4}$ crystals due to an inhomogeneous surface supersaturation field", J. Crystal Growth 213, pp. 340-354, 2000 .

9. H. Robey, R. Floyd, R. Torres and A. Burnham, "Impurity leach rates of 1000 liter growth tanks", Lawrence Livermore National Laboratory, Livermore, CA, UCRL-ID-133365, 1999.

10. L. N. Rashkovich and N. V. Kronsky, "Influence of $\mathrm{Fe}^{3+}$ and $\mathrm{Al}^{3+}$ ions on the kinetics of steps on the $\{100\}$ faces of KDP," J. Crystal Growth 182, pp. 434-441 (1997).

11. T.A. Land, T. L. Martin, S. Potapenko, G. T. Palmore, J.J. De Yoreo, "Recovery of surfaces from impurity poisoning during crystal growth", Nature 399, pp. 441-445, 1999.

12. Laser Focus World, July, 1999.

*Correspondence: Email: hawleyfedder1@Ilnl.gov; Telephone 925 422 6328; Fax: 9254223361 